\title{
Effect of applying adhesive after enamel etching on the shear bond strength of orthodontic brackets using light curing resin cements
}

\author{
Eung-Hyun Kim, Jin-Woo Kim, Se-Hee Park, Yoon Lee, Kyung-Mo Cho* \\ Department of Conservative Dentistry, College of Dentistry, Gangneung-Wonju National University, Gangneung, Republic of Korea
}

Purpose: The purpose of this study is to compare the shear bond strength of resin cement for orthodontic brackets without applying an adhesive primer, to the case of applying an adhesive primer. Materials and Methods: The specimens were divided into three experimental groups, Transbond XT, GC Ortho Connect and Orthomite LC, and the enamel surface was divided into two sections, one with $37 \%$ phosphoric acid and the other with $37 \%$ phosphoric acid and an adhesive primer or universal adhesive. Each of three types of cement was applied to orthodontic bracket, and after bonding, the shear bond strength was measured. Results: Transbond XT and Orthomite LC significantly increased shear bond strength when orthodontic brackets were bonded after applying an adhesive primer and universal adhesive, respectively. Conclusion: It is expected that application of an adhesive primer or universal adhesive after acid etching will improve shear bond strength of orthodontic brackets in Transbond XT and Orthomite LC. (J Dent Rehabil Appl Sci 2021;37(4):209-16)

Key words: enamel; orthodontic bracket; resin cement; shear bond strength

\section{서론}

치아 배열을 위한 교정 치료를 위해서는 브라켓을 치면 에 부착해야 하며 이때 여러가지 시멘트가 이용된다. 최 근에는 조작의 편의성과 높은 접착력으로 인하여 레진계 시멘트가 주로 이용된다. ${ }^{1}$

치아 배열을 위한 교정 치료를 위해서는 수 년에 걸친 긴 치료기간이 소요되기에 교정력 및 저작력 등의 기계적 인 힘과 온도 및 습도 변화에도 치열교정용 브라켓이 탈 락하지 않도록 접착력이 유지되어야 한다. ${ }^{2,3}$

레진계 재료들은 치아와 접착이 가능하지만 접착을 위 해서는 법랑질과 상아질 각각에 적절한 치아 표면 처리 및 접착제의 도포가 필요하며, 일반적으로 표면 산 부식 후 접착제를 도포한 뒤 광중합을 하게 된다. ${ }^{4,5}$

*Correspondence to: Kyung-Mo Cho

Professor, Department of Conservative Dentistry, College of Dentistry, Gangneung-Wonju National University, 7, Jukheon-gil, Gangneung, 25457, Republic of Korea

Tel: +82-33-640-2467, Fax: +82-33-640-3103, E-mail: drbozon@gwnu.ac.kr Received: September 25, 2021/Last Revision: October 13, 2021/Accepted:

October 26, 2021
또한 치아 배열을 위한 교정 치료를 위해서는 전체 치 아에 치열교정용 브라켓을 부착해야 하므로 치열교정용 브라켓 접착을 위한 치아 표면 처리에 매우 긴 시간이 소 요되며 복잡한 치면 처리 과정은 접착의 실패가 발생할 가능성을 크게 할 수 있다. ${ }^{6}$ 따라서 치열교정용 브라켓의 접착력 상실 혹은 치면으로부터의 탈락과 관련된 주제는 교정 영역의 주요 관심사로 자리잡게 되었다. ${ }^{7}$

최근 치열교정용 브라켓 접착을 위해 레진계 시멘트를 이용할 때 치아 표면의 산 부식 후 특별한 접착제를 도 포할 필요가 없는 제품들이 개발되었다. ${ }^{8}$ 치열교정용 브 라켓 전용 시멘트인 GC Ortho connect (GC, Tokyo, Japan) 및 Orthomite LC (Sun Medical, Shiga, Japan)는 제 조사의 지시에 따르면 법랑질의 산 부식만 시행한 후 접 착을 시행하도록 개발된 제품이다. 그러나 이러한 제품

Copyright $(2021$ The Korean Academy of Stomatognathic Function and Occlusion. (c) It is identical to Creative Commons Non-Commercial License. 
의 법랑질 접착력에 대한 연구는 거의 없으며 실제로 접 착이 잘 되는지 또는 기존의 치아 표면 처리 방법과 비교 하여 차이가 없는가에 관한 연구는 드물다.

이에 최근 개발되어 시판 중인 접착제 도포가 필요 없 는 치열교정용 브라켓 전용 시멘트의 법랑질에 대한 접 착강도를 접착제를 도포한 경우와 비교하여 유용성을 평 가하고자 하였다.

\section{연구 재료 및 방법}

치열교정용 브라켓 접착을 위한 광중합형 치열교정용 레진계 시멘트인 Transbond XT (3M Unitek, Monrovia, USA), GC Ortho Connect 및 Orthomite LC의 3종을 사용하였다. 법랑질 표면의 산 부식을 위해 $37 \%$ 인산인 DenFil Etchant 37\% (Vericom, Anyang, Korea), 접착제 인 Transbond XT Adhesive Primer (3M Unitek) 및 유 니버셜 접착제인 Single Bond Universal (3M ESPE, St. Paul, USA)을 사용하였다. 각 재료의 구성성분은 Table 1에 나타내었다.
치열교정용 브라켓으로 0.018-inch narrow twin standard edgewise bracket (Tomy, Fukushima, Japan)을 사 용하였다.

접착제와 시멘트의 중합을 위해 LED 광중합기인 GLight (GC)를 사용하였다.

치관부에 결함이 없는 소의 하악 절치 45 개를 사용하 였으며 발거 후 $4{ }^{\circ} \mathrm{C}$ 식염수에 보관하고 1 개월 이내에 사 용하였다. 백악법랑경계에서 치근을 절제한 후, 치관부 치수강의 치수를 제거하고 $2.5 \% \mathrm{NaOCl}$ 을 30분간 담가 둔 뒤 수세하고 근단 방향의 개방된 부분을 임시 충전재 인 Caviton (GC)으로 봉하였다. 치관의 최대한 넓은 순 측 면이 노출되도록 주의하여 $2 \times 2 \times 2 \mathrm{~cm}$ 크기의 자가 중합형 아크릴릭 투명 레진에 매몰하였다. 320-grit, 600grit의 실리콘 카바이드 페이퍼를 차례로 이용하여 균일 한 연마도를 가지는 법랑질 표면이 노출되도록 주수 하 에 연마하였다.

시편을 임의로 15 개씩 Transbond XT 군, GC Ortho Connect 군 및 Orthomite LC 군으로 분류하였다. 각 접 착 시스템을 법랑질 표면에 적용하기 전에 표면은 깨끗

Table 1. Composition of materials used in this study

\begin{tabular}{|c|c|c|}
\hline Material & Manufactures & Composition \\
\hline $\begin{array}{c}\text { Transbond XT } \\
\text { Paste }\end{array}$ & 3M Unitek & $\begin{array}{l}\text { Silane-treated quartz } \\
\text { Bisphenol A diglycidyl ether dimethacrylate } \\
\text { Bisphenol A bis (2-hydroxyethil ether) dimethacrylate }\end{array}$ \\
\hline GC Ortho Connect & GC & $\begin{array}{l}\text { Ethoxylated bisphenol-A dimethacrylate (Bis-EMA) } \\
\text { Urethane dimethacrylate (UDMA) } \\
\text { Phosphoric acid ester monomer } \\
\text { Photoinitiator } \\
\text { Stabilizer }\end{array}$ \\
\hline Orthomite LC & Sun Medical & $\begin{array}{l}\text { 2-Hydroxyethly methacrylate } \\
\text { 2-Propenoic acid, 2-methyl-, 7,7,9-trimethyl-4,13 dioxo } \\
\text {-3, 14-dioxa-5,12-diazahexadecane-1, 16-diyl ester } \\
\text { 2-Propenoicacid, 2-methyl-, 1,3-phenylenebis }\end{array}$ \\
\hline $\begin{array}{l}\text { Transbond XT } \\
\text { Adhesive Primer }\end{array}$ & 3M Unitek & $\begin{array}{l}\text { TEGDMA } \\
\text { Bis-GMA } \\
\text { 4-(dimethylamino)-benzeneethanol } \\
\text { DL-Camphorquinone } \\
\text { Hydroquinone }\end{array}$ \\
\hline $\begin{array}{l}\text { Single Bond } \\
\text { Universal }\end{array}$ & 3M ESPE & $\begin{array}{l}\text { Bis-GMA } \\
\text { MDP } \\
\text { Dimethacrylate resins } \\
\text { HEMA } \\
\text { Vitrebond copolymer } \\
\text { Silane } \\
\text { Ethanol } \\
\text { Water }\end{array}$ \\
\hline
\end{tabular}

Data from manufacturers' websites and/or product catalogs. 
하게 세척하고 건조한 후 각각 다른 치면 처리를 하였다.

법랑질 표면을 두 부분으로 나누어 각각의 시멘트 별 로 두 가지 다른 표면 처리를 하였다. 세 가지 시멘트 모 두 산 부식만 시행한 군은 $37 \%$ 인산을 법랑질 표면에 적 용하고 30 초간 산 부식한 뒤 30초간 수세하고 건조하였 으며 추가적인 접착제를 처리한 군은 다음과 같이 하였 다.

Transbond XT 시멘트에서는 37\% 인산을 법랑질 표 면에 적용하고 30 초간 산 부식한 뒤 30 초간 수세한 후 건 조하고, Transbond XT Primer를 얇게 도포한 뒤 10초간 바람으로 건조하고 10 초간 광중합을 하였다.

GC Ortho Connect 시멘트와 Orthomite LC 시멘트 에서는 $37 \%$ 인산을 법랑질 표면에 적용하고 30 초간 산 부식한 뒤 30초간 수세한 후 건조하였으며, Single Bond Universal을 얇게 도포하고 10 초 후 바람으로 건조한 뒤 10 초간 광중합 하였다.

단면적 $10.6 \mathrm{~mm}^{2}$ 의 하악 절치용 금속 브라켓에 각각 의 시멘트를 혼합하여 적용하고 표면 처리를 한 치면에 안착한 후 잉여 시멘트를 제거한 뒤 브라켓의 양쪽에서 $\mathrm{LED}$ 광중합기(G-Light)를 이용하여 10 초씩 광중합을 하여 접착을 하였으며 24 시간 동안 $36^{\circ} \mathrm{C}, 100 \%$ 상대습 도에서 보관하였다.

전단접착강도 측정을 위해 만능 재료 시험기(RB-306, R\&B Inc., Daejeon, Korea)를 사용하였다. 각 시편에 $400 \mathrm{~kg}$ 중의 전단력을 분당 $1.0 \mathrm{~mm}$ 의 속도로 가하여 금 속 브라켓이 시편으로부터 탈락할 때의 최대하중을 RB 306 Helio X software (R\&B Inc.)를 이용하여 획득하고 이를 전단접착강도 $(\mathrm{MPa})$ 로 환산하였다.

$\mathrm{R}(\mathrm{MPa})=\mathrm{F}(\mathrm{N}) / \mathrm{A}\left(\mathrm{mm}^{2}\right)$
전단접착강도 측정 후, 시편의 표면을 실물 현미경 (LEICA M320, Leica Microsystems, Wetzlar, Germany) 으로 40 배 확대하여 접착 실패 양상을 관찰하였다. 접착 실패 유형에 따라 접착제와 피착면 사이에서 발생하는 접착성 실패(Adhesive failure), 접착제 내에서 발생하는 응집성 실패(Cohesive failure), 위의 양상들이 혼합되어 나타나는 혼합성 실패(Mixed failure)의 3가지 범주로 분 류하였다.

시멘트 종류와 치면 처리 방법이 전단접착강도에 미치 는 영향을 평가하기 위하여 이원배치 분산분석(Two-way ANOVA)을 하였고, 각각의 시멘트에서 표면 처리 방법 에 따른 전단접착강도의 유의성을 검증하기 위하여 독립 t-검정(Independent t-test)을 하였다. 모든 실험 조건 사 이의 전단접착강도를 다중비교하기 위하여 일원배치 분 산분석(One-way ANOVA)을 시행하였으며 Duncan test 로 사후분석을 하였다. 모든 통계 분석은 $95 \%$ 유의수준 에서 진행을 하였다.

\section{결과}

시멘트와 표면 처리 방법이 전단접착강도에 미치는 영 향에 대한 이원배치 분산분석 결과를 Table 2와 Fig. 1에 나타내었다. 통계 분석에 의하면 본 연구에서 표면 처리 는 전단접착강도에 유의한 영향을 주는 요소로 나타났 으며, 접착제 혹은 유니버셜 접착제를 도포한 후 접착을 하였을 때 전단접착강도가 증가하는 경향을 나타내었다. 시멘트의 종류에 따른 전단접착강도의 차이는 나타나지 않았다.

각각의 시멘트에서 표면 처리 방법에서 나타난 전단접

Table 2. Result of Two-way ANOVA test on shear bond strength of cements

\begin{tabular}{|c|c|c|c|c|c|}
\hline Source & Sum of squares & $\mathrm{df}$ & Mean square & $\mathrm{F}$ & Sig. \\
\hline Corrected Model & 302.471 & 5 & 60.494 & 2.431 & .041 \\
\hline Intercept & 52301.824 & 1 & 52301.824 & 2102.178 & .000 \\
\hline Cement & 63.254 & 2 & 31.627 & 1.271 & .286 \\
\hline Surface & 229.760 & 1 & 229.760 & 9.235 & .003 \\
\hline Cement*Surface & 9.456 & 2 & 4.728 & 0.190 & .827 \\
\hline Error & 2089.905 & 84 & 24.880 & & \\
\hline Total & 54694.200 & 90 & & & \\
\hline Corrected Total & 2392.376 & 89 & & & \\
\hline
\end{tabular}

a.R Squared $=.126$ (Adjusted R Squared $=.074)$, df: Degree of freedom, Sig.: Significance. 


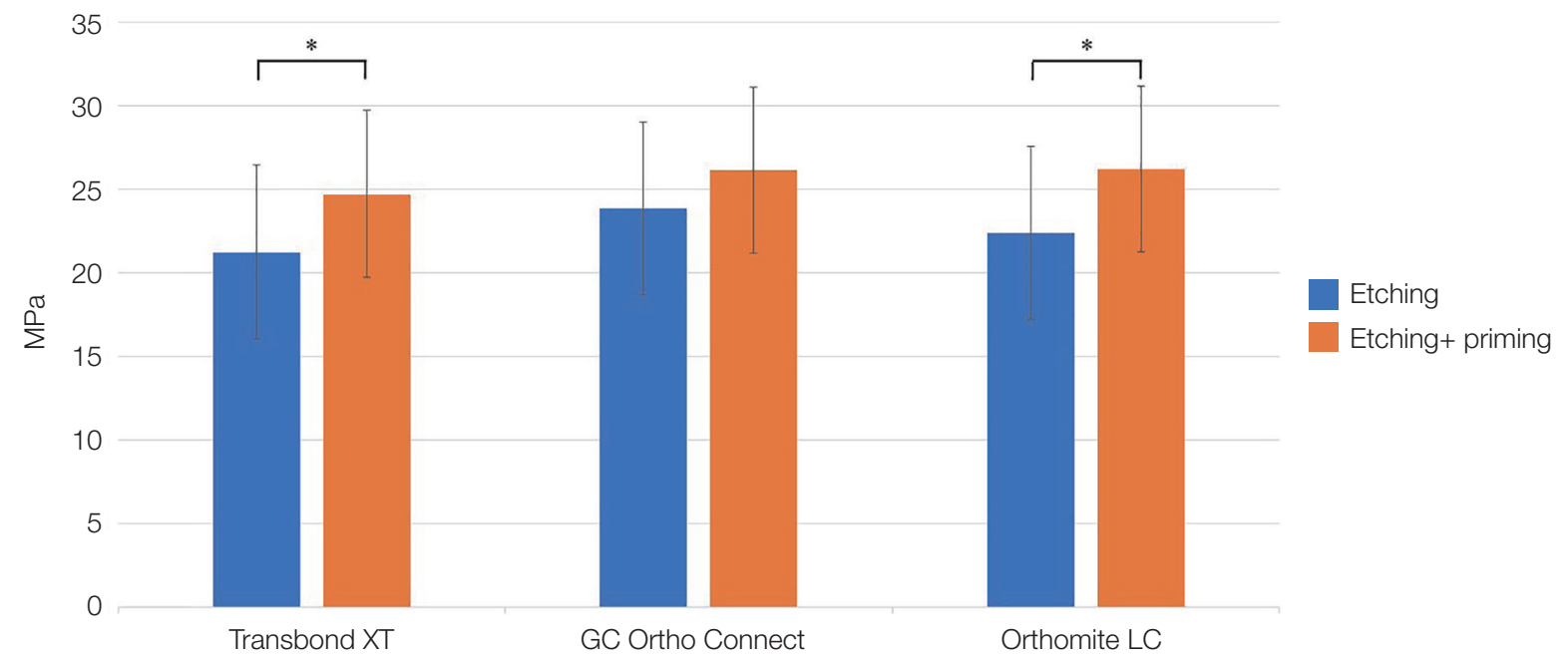

Fig. 1. Result of Two-way ANOVA test on shear bond strength of cements. The groups with statistically significant differences are denoted by an asterisk $(P<0.05)$.

Table 3. Shear bond strength of tested groups (Mean (MPa) \pm St. Deviation)

\begin{tabular}{|c|c|c|c|}
\hline & Transbond XT & GC Ortho Connect & Orthomite LC \\
\hline Etching & $21.25 \pm 4.317_{*}$ & $23.86 \pm 5.39$ & $22.41 \pm 5.207_{*}$ \\
\hline Etching + Priming & $24.73 \pm 4.97]^{*}$ & $26.16 \pm 5.56$ & $26.23 \pm 4.35]^{*}$ \\
\hline
\end{tabular}

The groups with statistically significant differences are denoted by an asterisk $(P<0.05)$.

착강도의 평균과 표준편차 그리고 독립 t-검정을 시행하 여 각 시멘트 군에서의 표면 처리 방법에 따른 전단접착 강도를 비교한 결과를 Table 3에 나타내었다. Transbond XT 군과 Orthomite LC 군에서 접착제를 도포한 후 접 착을 한 경우 전단접착강도가 유의하게 증가하였으며, GC Ortho Connect 군에서는 표면 처리 방법에 따른 전 단접착강도의 차이가 나타나지 않았다.

모든 실험 조건 사이의 전단접착강도를 일원배치 분산 분석 후 Duncan test로 사후분석을 한 결과는 Table 4에 나타내었다. 산 부식만 한 Transbond XT 군이 산 부식 을 하고 유니버셜 접착제를 도포한 GC Ortho Connect 군 및 Orthomite LC 군에 비하여 낮은 전단접착강도를 보였다.

각 실험군에서의 접착 실패 양상을 Table 5 에 나타내었 으며, 모든 실험군에서 대부분 혼합성 실패가 관찰되었다.
Table 4. Result of One-way ANOVA test on shear bond strength

\begin{tabular}{lccc}
\hline & \multicolumn{3}{c}{ Homogeneous subsets } \\
& N & 1 & 2 \\
\hline Transbond Etching & 15 & 21.25 & \\
Transbond Priming & 15 & 22.41 & 22.41 \\
Ortho Connect Etching & 15 & 23.86 & 23.86 \\
Ortho Connect SBU & 15 & 24.73 & 24.73 \\
Orthomite Etching & 15 & & 26.16 \\
Orthomite SBU & 15 & & 26.23 \\
\hline
\end{tabular}


Table 5. Failure mode of tested groups (Number of specimen)

\begin{tabular}{ccccc}
\hline & Cohesive & Adhesive & Mixed & Total \\
\hline Transbond Etching & 1 & 1 & 13 & 15 \\
Transbond Priming & 0 & 2 & 13 & 15 \\
Ortho Connect Etching & 1 & 1 & 13 & 15 \\
Ortho Connect SBU & 2 & 1 & 12 & 15 \\
Orthomite Etching & 1 & 0 & 14 & 15 \\
Orthomite SBU & 0 & 0 & 15 & 15 \\
\hline
\end{tabular}

\section{고찰}

치열교정용 브라켓의 접착 실험을 위한 가장 이상적인 치아는 사람의 상악 중절치로 순면으로부터 거의 편평한 접착면을 확보할 수 있어 치열교정용 브라켓 접착 시 곡 면에 대한 고려사항을 배제할 수 있다. ${ }^{9}$ 하지만 최근 심미 성에 대한 관심과 여러 치료 술식의 발달로 사람의 상악 중절치를 연구용으로 구하기는 매우 어렵다.

모든 포유류의 치아는 조직학적으로 비슷한 구조를 보 이며, ${ }^{10}$ Nakamichi 등의 연구에 의하면 비록 소의 법랑질 은 사람의 법랑질에 비하여 낮은 접착력을 보이나 접착 력에 통계적으로 유의한 차이를 나타내지 않았다. ${ }^{11-13}$ 따 라서 본 연구에서는 소의 법랑질을 사람의 법랑질의 대 체재로써 사용하여 치열교정용 브라켓의 접착 실험을 하 였다.

치열교정용 브라켓 접착 술식에 소요되는 시간을 줄이 기 위하여 접착제 도포가 필요치 않은 시멘트들이 도입 되었다. 이전의 다른 연구들에 의하면 이러한 시멘트들은 기존 방식의 접착 시스템과 비교하였을 때 비슷하거나 ${ }^{14}$ 약간 낮은 ${ }^{15}$ 전단접착강도를 나타내었다.

Reynolds의 연구에 의하면 치열교정용 브라켓이 구강 내에서 유지되기 위한 임상적으로 허용되는 최소 전단접 착강도는 5.9 - $7.8 \mathrm{MPa}$ 이며, ${ }^{2}$ 본 연구에서 실험군들 간 전단접착강도의 유의한 차이는 나타나지 않았으나 모든 실험군에서 표면 처리 방법에 관계없이 Reynolds가 제시 한 기준을 만족시켰다.

접착제와 법랑질 표면 사이의 결합 강도는 레진의 강 도 및 법랑질 표면 공극으로 침투하는 능력에 의해 영향 을 받는다. ${ }^{16,17}$ 법랑질의 활택한 표면은 산 부식에 의해 거칠어지며 불균일한 미세요철이 생겨남으로써 접착할 수 있는 표면적이 증가된다. 부식된 법랑질의 표면장력은 약 $72 \mathrm{mN} / \mathrm{m}$ 으로서 부식되지 않은 상태와 비교하였을
때 약 2 배가량 증가하게 되어 소수성의 레진용액이 모세 혈관작용에 의해 표면 공극에 침윤해 들어갈 수 있게 된 다. ${ }^{18}$ 이러한 법랑질의 특성으로 인하여 본 연구에서 표면 처리 여부에 관계없이 모든 실험군에서 높은 전단 접착 강도를 나타낸 것으로 보인다.

본 연구에서 이원배치 분산분석을 이용하여 시멘트와 표면 처리 방법 사이의 관계를 평가하였을 때, 산 부식 후 접착제 처리를 시행한 경우 산 부식만 시행한 경우에 비 하여 전단접착강도가 증가하는 경향을 나타내었다. 자가 부식 접착제의 법랑질에 대한 접착은 부식 처리된 법랑질 에 레진 단량체가 침투되어 형성된 미세기계적인 유지에 의해 이루어지며, ${ }^{19,20}$ 접착제는 일반적으로 휘발성이 높 은 유기 용매에 레진 모노머를 주성분으로 포함하고 있 기 때문에 산 부식 후 형성된 공극으로의 레진 침투를 용 이하게 하는 역할을 한다. ${ }^{21}$ 본 연구에서도 마찬가지로 접착제 및 자가 부식 접착제를 이용한 표면 처리가 접착 강도 증가에 기여했을 것으로 추측할 수 있다.

각 시멘트에서 표면 처리 방법 사이의 관계를 평가하였 을 때, Transbond XT 군과 Orthomite LC 군에서 산 부 식 후 접착제 처리를 하였을 때 산 부식 처리만 한 경우 에 비하여 유의하게 높은 전단접착강도를 나타내었으며, GC Ortho Connect 군에서는 전단접착강도에 통계적으 로 유의한 차이를 나타내지 않았다. 이는 각 제품 성분의 차이에서 기인한 결과로 추측된다. Transbond XT Paste 는 제조사에 따르면 필러 함량이 $70-80 \%$ 가량의 무게비 를 차지하며, 레진 단량체는 무게비가 $15-30 \%$ 가량으 로 상대적으로 낮은 비율을 함유하고 있다. Transbond XT Primer에는 소수성 모노머인 Bis-GMA와 점도를 낮 추기 위한 TEG-DMA가 주성분으로 구성되어 있으며 Transbond XT Paste의 상대적으로 낮은 레진 단량체 비 율을 Transbond XT Primer가 보완해주어 치면과의 접 착력을 향상시키는 것으로 생각된다. Orthomite LC는 
제조사에 따르면 4 종의 레진 단량체가 각각 $10 \%$ 이하 의 무게비로 포함되어 있으며, GC Ortho Connect는 제 조사에 따르면 Bis-EMA와 UMDA를 각각 무게비로 10 - 30\%가량을 함유하고 있다. Orthomite LC는 다른 제 품군과 비교하였을 때 레진 단량체의 비율이 상대적으로 낮으므로, 자가 부식 접착제인 Single Bond Universal이 접착력을 향상시키는 요인으로 작용하였을 것이라 추측 할 수 있다. ${ }^{8}$

Hosein 등의 연구에 의하면 브라켓 접착용 시멘트의 접착력이 높을수록 브라켓 제거 후 남아있는 잔사의 양 이 더욱 많은 경향을 나타낸다. ${ }^{22,23}$ 본 연구에서 치열교정 용 시멘트의 접착 실패 양상은 모든 군에서 대부분 혼합 성 실패 양상을 나타내었으며, 치면에 남아있는 치열교정 용 시멘트 잔사의 면적을 비교해 본다면 임상적으로 치 열교정용 브라켓 제거 후 활택한 치면을 만드는 데 유리 한 시멘트를 선택할 수 있을 것으로 생각한다.

한편 이번 연구는 열순환자극, 정적 또는 동적 하중부 여가 없는 상황에서 합착한 후 24시간 후에만 이루어졌 으므로 시멘트의 내구성에 영향을 주는 다양한 상황을 부여하였을 때 나타나는 결과에 대한 추가 연구가 필요 하다.

\section{결론}

모든 실험군에서 시멘트의 종류와 표면 처리 방법에 관 계없이 치열교정용 브라켓을 위한 최소 전단접착강도를 만족시켰으며, 산 부식만 한 Transbond XT 군이 산 부식 을 하고 유니버셜 접착제를 도포한 GC Ortho Connect 군 및 Orthomite LC 군에 비하여 낮은 전단접착강도를 보였다.

Transbond XT와 Orthomite LC는 산 부식만 시행하 는 것보다 산부식 후 접착제 또는 유니버셜 접착제를 사 용하는 것이 치열교정용 브라켓의 전단접착강도를 증가 시켰다.

이상의 결과를 종합해 볼 때, 산 부식만으로 접착을 유 도하는 치열교정용 레진계 시멘트인 GC Ortho Connect와 Orthomite LC의 사용시에 제조사의 지시에 따 라 법랑질 산 부식 만을 하고 사용하여도 충분한 접착력 을 얻을 수 있을 것으로 생각하며 Transbond XT와 Orthomite LC에서 부가적인 강한 접착력이 필요한 경우 산 부식 후 접착제의 적용이 치열교정용 브라켓의 전단접착 강도를 향상시킬 것으로 기대한다.

\section{ORCID}

Eung-Hyun Kim https://orcid.org/0000-0002-2251-1691

Jin-Woo Kim https://orcid.org/0000-0002-0004-0710

Se-Hee Park https://orcid.org/0000-0002-4052-4082

Yoon Lee https://orcid.org/0000-0001-9813-8531

Kyung-Mo Cho https://orcid.org/0000-0003-3464-9425

\section{References}

1. Sharma S, Tandon P, Nagar A, Singh GP, Singh A, Chugh VK. A comparison of shear bond strength of orthodontic brackets bonded with four different orthodontic adhesives. J Orthod Sci 2014;3:29-33.

2. Reynolds I. A review of direct orthodontic bonding. Br J Orthod 1975;2:171-8.

3. Bishara SE, Khowassah MA, Oesterle LJ. Effect of humidity and temperature changes on orthodontic direct-bonding adhesive systems. J Dent Res 1975; 54:751-8.

4. Kanca 3rd J. Resin bonding to wet substrate. I. Bonding to dentin. Quintessence Int 1992;23:39-41.

5. Toledano M, Osorio R, De Leonardi G, RosalesLeal JI, Ceballos L, Cabrerizo-Vilchez MA. Influence of self-etching primer on the resin adhesion to enamel and dentin. Am J Dent 2001;14:205-10.

6. Matasa CG. Microbial attack of orthodontic adhesives. Am J Orthod Dentofacial Orthop 1995;108: 132-41.

7. Rasmussen MJ, Togrye C, Trojan TM, Tantbirojn D, Versluis A. Post-gel shrinkage, elastic modulus, and stress generated by orthodontic adhesives. Angle Orthod 2020;90:278-84.

8. Scribante A, Sfondrini MF, Fraticelli D, Daina P, Tamagnone A, Gandini P. The influence of noprimer adhesives and anchor pylons bracket bases on shear bond strength of orthodontic brackets. Biomed Res Int 2013;2013:315023.

9. Oesterle LJ, Shellhart WC, Belanger GK. The use of bovine enamel in bonding studies. Am J Orthod Dentofacial Orthop 1998;114:514-9.

10. Suga S, Kondo M, Onodera A, Kubota Y, Ohtsuka M. Electron microprobe analyses on the distributions of $\mathrm{Cl}, \mathrm{Mg}$ and $\mathrm{Na}$, in the enamels of various 
animals. Jap J Oral Biol 1971;13:85-94.

11. Reis AF, Giannini M, Kavaguchi A, Soares CJ, Line SR. Comparison of microtensile bond strength to enamel and dentin of human, bovine, and porcine teeth. J Adhes Dent 2004;6:117-21.

12. Nakamichi I, Iwaku M, Fusayama T. Bovine teeth as possible substitutes in the adhesion test. J Dent Res 1983;62:1076-81.

13. Sfondrini MF, Scribante A, Cacciafesta V, Gandini P. Shear bond strength of deciduous and permanent bovine enamel. J Adhes Dent 2011;13:227-30.

14. Naidu E, Stawarczyk B, Tawakoli PN, Attin R, Attin T, Weigand A. Shear bond strength of orthodontic resins after caries infiltrant preconditioning. Angle Orthod 2013;83:306-12.

15. Murray SD, Hobson RS. Comparison of in vivo and in vitro shear bond strength. Am J Orthod Dentofacial Orthop 2003;123:2-9.

16. Kitayama S, Nikaido T, Ikeda M, Foxton RM, Tagami J. Enamel bonding of self-etch and phosphoric acid-etch orthodontic adhesive systems. Dent Mater J 2007;26:135-43.

17. Shinchi MJ, Soma K, Nakabayashi N. The effect of phosphoric acid concentration on resin tag length and bond strength of a photo-cured resin to acidetched enamel. Dent Mater 2000;16:324-9.

18. Jendresen MD, Glantz PO, Baier RE, Eick JD. Microtopography and clinical adhesiveness of an acid etched tooth surface: an in-vivo study. Acta Odontol Scand 1981;39:47-53.

19. Hara AT, Amaral CM, Pimenta LA, Sinhoreti MA. Shear bond strength of hydrophilic adhesive systems to enamel. Am J Dent 1999;12:181-4.

20. Frankenberger R, Krämer N, Petschelt A. Longterm effect of dentin primers on enamel bond strength and marginal adaptation. Oper Dent 2000; 25:11-9.

21. Hellak A, Rusdea P, Schauseil M, Stein S, Korbmacher-Steiner HM. Enamel shear bond strength of two orthodontic self-etching bonding systems compared to Transbond ${ }^{\mathrm{TM}}$ XT. J Orofac Orthop 2016; 77:391-9.

22. Hosein I, Sherriff M, Ireland AJ. Enamel loss during bonding, debonding, and cleanup with use of a self-etching primer. Am J Orthod Dentofacial Or- thop 2004;126:717-24.

23. Pithon MM, dos Santos RL, de Oliveira MV, de Oliveira Ruellas AC, Romano FL. Metallic brackets bonded with resin-reinforced glass ionomer cements under different enamel conditions. Angle Orthod 2006;76:700-4. 


\section{광중합형 레진시멘트를 사용한 치열교정용 브라켓 접착 시 접착제 사용 유무가 산 부식한 법랑질의 전단접착강도에 미치는 영향}

김응현 전공의, 김진우 교수, 박세희 교수, 이윤 교수, 조경모 교수*

강릉원주대학교 치과대학 치과보존학교실

목적: 본 연구의 목적은 접착제를 적용하지 않고 치열교정용 브라켓을 접착할 수 있는 레진시멘트의 법랑질에 대한 접착 강도를 접착제를 적용한 경우와 비교하기 위함이다.

연구 재료 및 방법: 시편을 Transbond XT, GC Ortho Connect 및 Orthomite LC의 3개의 실험군으로 나누고, 노출된 법 랑질 표면을 2 분획으로 나누어 한 분획에는 $37 \%$ 인산으로, 다른 한 분획에는 $37 \%$ 인산 및 접착제 혹은 유니버셜 접착제 로 표면 처리를 하였다. 치열교정용 브라켓에 3 종류의 시멘트를 각각 도포하고 접착을 한 뒤 전단접착강도를 측정하였다. 결과: Transbond XT와 Orthomite LC는 각각 접착제와 유니버셜 접착제를 적용한 후 치열교정용 브라켓을 접착할 경 우 전단접착강도가 유의하게 증가하였다.

결론: Transbond XT와 Orthomite LC에서 산 부식 후 접착제의 적용이 치열교정용 브라켓의 전단접착강도를 향상시킬 것으로 기대한다.

(구강회복응용과학지 2021;37(4):209-16)

주요어: 법랑질; 치열교정용 브라켓; 레진시멘트; 전단접착강도

*교신저자: 조경모

(25457) 강원도 강릉시 죽헌길 7 강릉원주대학교 치과대학 치과보존학교실

Tel: 033-640-2467 | Fax: 033-640-3103 | E-mail: drbozon@gwnu.ac. kr

접수일: 2021년 9월 25일 | 수정일: 2021년 10월 13일 | 채택일: 2021년 10월 26일 